\title{
Fibrose congênita de reto inferior atípica com hipotonia muscular generalizada: relato de um caso
}

\author{
Atipical inferior rectus congenital fibrosis with generalizated \\ muscular hypotonia: case report
}

Ezon Vinicius Alves Pinto Ferraz ${ }^{(1)}$ Keila Miriam Monteiro de Carvalho ${ }^{(2)}$ Luis Carlos Peixoto Rocha ${ }^{(3)}$ (in memorian) Leopoldo Magacho dos Santos Silva ${ }^{(4)}$
Trabalho realizado na Seção de estrabismo do Departamento de Oftalmologia da UNICAMP.

(1) Médico assistente do departamento de Oftalmologia / Otorrino da Universidade Estadual de Campinas UNICAMP.

(2) $\operatorname{Prof}^{\mathrm{a}}$. Dr ${ }^{\mathrm{a}}$. Assistente e Chefe do setor de estrabismo da UNICAMP.

(3,4) Médicos Residentes de Oftalmologia da UNICAMP.

Endereço para correspondência: Rua Hermantino Coelho, 77, apto. 71, B1 -1. Mansões Sto Antonio. Campinas (SP) CEP 13087-500.

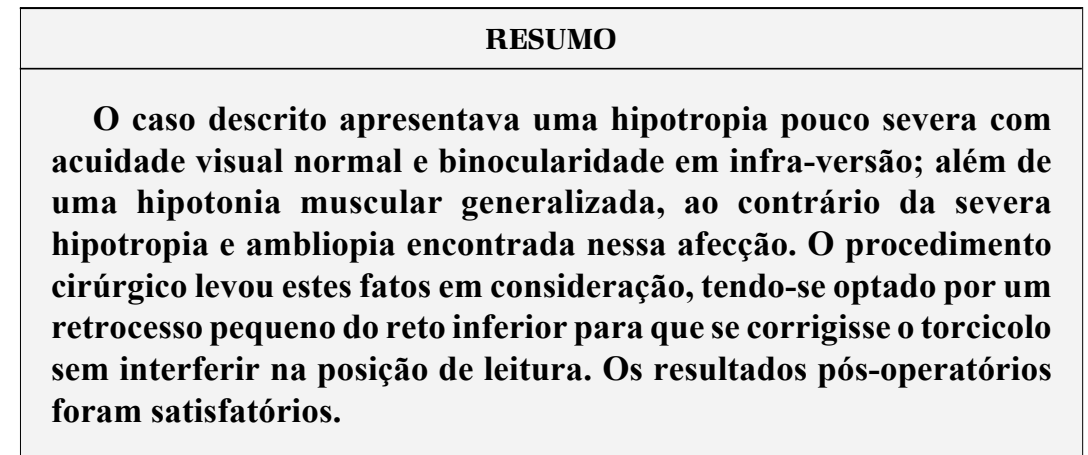

Palavras-chave: Fibrose congênita de reto inferior; Ambliopia; Hipotonia muscular generalizada.

\section{INTRODUÇ̃̃̃O}

A fibrose congênita de reto inferior (FCRI) é uma entidade clínica rara, de etiologia desconhecida e sem incidência familiar ${ }^{1}$. Trata-se de pacientes com severa hipotropia e marcada limitação da elevação tanto ativa quanto passiva $^{2}$.

A afecção é unilateral e pode acompanhar-se de blefaroptose e esotropia, porém na grande maioria dos casos trata-se de pseudoptose devida a hipotropia, que desaparece com a correção desta ${ }^{2}$. A contratura do músculo envolvido não é secundária à paralisia dos elevadores pois a elevação melhora ou se recupera totalmente com o debilitamento do reto inferior, que não ocorre na paralisia dos elevadores ${ }^{3}$. Os casos descritos na literatura descrevem ambliopia de difícil controle mesmo com tratamento precoce e bem realizado ${ }^{4}$.

O tratamento é cirúrgico, através de retrocesso máximo do reto inferior ${ }^{6}$, de modo a permitir elevação passiva do olho até $10^{\circ}$, tomando-se os cuidados necessários para liberar as conexões entre a pálpebra inferior e a bainha do reto inferior (ligamento de Lockwood), evitando com isso a retração da pálpebra inferior, de aspecto estético indesejável ${ }^{4}$. A cirurgia pode ser combinada , segundo a severidade da restrição com tenotomias marginais ${ }^{6}$.

\section{DESCRIÇÃO DO CASO}

O menor RRSO, foi atendido no setor de estrabismo do Departamento de Oftalmologia do Hospital das Clínicas da UNICAMP em fevereiro de 1995, com 6 anos de idade e história de olho torto desde o nascimento, sendo que a mãe referia que havia percebido o desvio desde poucos meses 


\section{ANÚNCIO}


de idade e que a fenda palpebral direita era um pouco mais estreita que a esquerda e que ainda o olho direito tinha limitação de movimentação para cima em relação ao contra-lateral.

Com o crescimento refere ainda a mãe que o desvio ficou mais acentuado, passando a perceber que a criança inclinava a cabeça ligeiramente para a direita levantando ao mesmo tempo o queixo para olhar os objetos.

A mãe contou que a criança nunca usara óculos ou feito oclusão de algum olho e que havia deixado-a sem tratamento até então devido ao fato dela ter apresentado um atraso no desenvolvimento motor decorrente da hipotonia muscular generalizada a qual foi exaustivamente investigada pela neurologia chegando-se a um diagnóstico, por exclusão, de hipotonia muscular benigna. Somente após este fato é que ela resolveu procurar o tratamento oftalmológico.

No primeiro exame foi encontrado o torcicolo: (figura 1): A cabeça inclinada para direita e com queixo elevado. Acuidade visual de 1,0 em ambos os olhos (AO) sem correção, refração estática de $+0,75 \mathrm{AO}$; biomicroscopia e fundoscopia sem alterações; estereopsia de 60" (Titmus).

As medidas do desvio foram feitas pelo método do cover teste, nas nove posições diagnósticas.

Pré-operatório:

$\begin{array}{cccc} & \text { HT E/D 35 } & \text { HT E/D 25 } & \text { HT E/D 25 } \\ \text { Longe: } & \text { HT E/D16 } & \text { HT E/D14 } & \text { HT E/D 14 } \\ & \text { RAC } & \text { RAC } & \text { RAC }\end{array}$

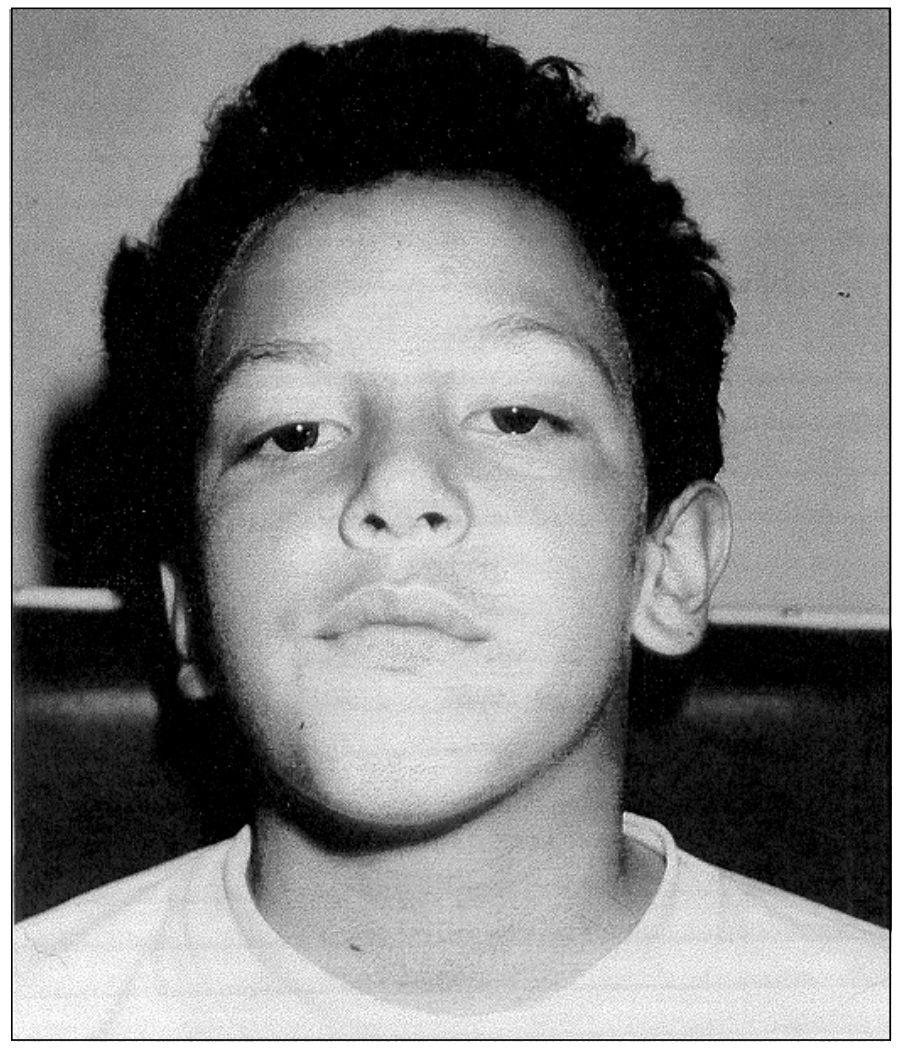

Fig. 1 - Posição da cabeça no pré-operatório.
As versões mostravam -4 RSD, -3 OID, -2 RID e -1 OSD, a ducção ativa era de -4 RSD, -3 OID e -1 RID. Ao teste de ducção passiva o paciente apresentava restrição de elevação do olho direito, que não passava da linha média no meridiano horizontal.

Foi feita a hipótese diagnóstica de FCRI e indicada cirurgia corretiva, a qual foi realizada em fevereiro de $1998 \mathrm{com}$ retrocesso do reto inferior de $5 \mathrm{~mm}$. Ao exame per-operatório o reto inferior encontrava-se com aspecto fibroso e inelástico.

A avaliação pós-operatória mostrou discreto torcicolo (figura 2): a cabeça inclinada para direita, sem elevação do queixo; resultado considerado satisfatório.

Pós-operatório:

$\begin{array}{cccc} & \text { HT E/D 16 } & \text { HT E/D 12 } & \text { HT E/D 6 } \\ \text { Longe: } & \text { RAC } & \text { RAC } & \text { RAC } \\ & \text { HT D/E 6 } & \text { HT D/E 6 } & \text { HT D/E 4 }\end{array}$

\section{DISCUSSÃO}

A FCRI é descrita na literatura como responsável por hipotropias severas acompanhadas de pseudoptose e ambliopia ${ }^{1}$. No caso descrito a atipia se manifestou não só devido ao fato da hipotropia não ser severa como também por haver acuidade visual normal e binocularidade em infraversão. O procedimento cirúrgico levou estes fatos em consideração, sendo optado um

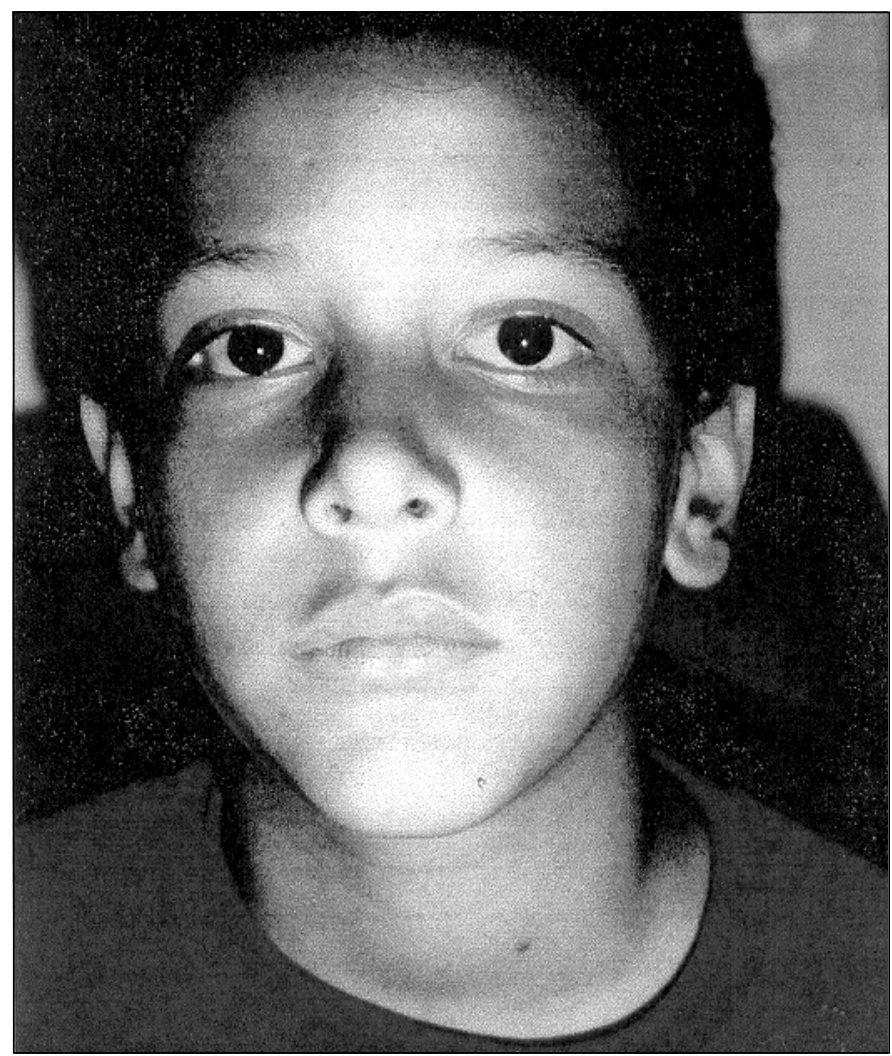

Fig. 2 - Posição da cabeça no pós-operatório. 
Fibrose congênita de reto inferior atípica com hipotonia muscular generalizada: relato de um caso

\section{ANÚNCIO}


retrocesso pequeno do reto inferior para que se corrigisse o torcicolo sem interferir muito na posição de leitura. Foi verificado que a diminuição da limitação de elevação pós-operatória foi pequena, o que poderia sugerir que o plano foi hipocorretor, porém verificou-se também uma inversão do desvio vertical em infraversão o qual mostrou que para um músculo inelástico, como já era esperado, um retrocesso maior poderia ser desastroso.

A associação da FCRI com Hipotonia Muscular Benigna nunca foi descrita na literatura, embora em dois casos estudados à luz da microscopia eletrônica, tenham sido verificadas trocas miopáticas que sugeriram a relação desta entidade com as distrofias musculares. Harley e colaboradores, analisando uma série de pacientes, chegaram às mesmas conclusões, levantando a hipótese de que a FCRI faça parte da "Fibrose Generalizada de Brown”, porém numa forma monosintomática ${ }^{2}$.

\section{SUMMARY}

A case report of an atipical inferior rectus congenital fibrosis associated with a generalized muscular hypotonia is presented. It shows mild hipotropia with a normal visual acuity and binocularity in infraversion position contrasting with the severe hipotropia and ambliopy found. The surgical procedure took these facts into consideration, so we performed a small retrocess of the muscle with the objective to correct the head position without changes in the reading position. The postoperative results were satisfactory.

Keywords: Inferior rectus fibrosis; Ambliopy; Generalized muscular hipotony.

\section{REFERÊNCIAS BIBLIOGRÁFICAS}

1. Harley R, Rodrigues M, Crawford J. Congenital fibrosis of the extraocular muscles. J Ped Ophthalm, Strab 1978;15:346.

2. Prieto Díaz, Souza Dias. Fibrosis Congénita del Recto Inferior. In: Estrabismo. 2a ed., São Paulo, Roca, 1986;517-19.

3. Scott W \& Jackson OB. Double elevator palsy. The significance of the inferior rectus restriction. Am Orthopt J 1977;27:5.

4. Barbosa PH. Fibroses Congênitas dos Músculos Oculomotores. In: SouzaDias CH, Almeida, H. Estrabismo, $3^{\text {a }}$ ed, São Paulo, Roca, 1993;214-5.

5. Goldstain JH. The intraoperative forced duction test. Report of a case of congenital fibrous bands. Arch Ophtalmol 1964;72:647.

6. Prieto-Díaz J, Languens R. Fibrosis congénita del recto inferior. Estudio clínico y ultraestructural. Arch Oftalmol B Aires 1973;48:301.

- XXiX Simpósio da Associação Paranaense de Oftalmologia

- VI Simpósio Sul Brasileiro de Catarata

- VI Simpósio Sul Brasileiro de Cirurgia Refrativa e Implantes

Intra-OCULARES

\title{
03 E 04 DE DEZEMBRO DE 1999
}

\section{Local: CIETEP/FIEP - CURITIBA - PARANÁ}

\section{Coordenador Geral: Dr. Hamilton Moreira}

\author{
IN F O R M A C Õ E S \\ Soft Planejamento e Organização de Eventos Ltda. \\ E-mail: $\quad$ soft.eventos@mais.sul.com.br
}

